\title{
Tips for Integrating Land and Wildlife Management: Quail in Cattle Country ${ }^{1}$
}

\author{
William M. Giuliano and Lauren Watine ${ }^{2}$
}

In Florida, changes in land management practices during the past $50+$ years have led to declines in quail habitat and populations. Important changes involve the use of fire, conversion of native range to improved pastures and hayfields, and overgrazing. This has led to habitat that lacks the plant species and structural diversity required for quail.

Bobwhites are a disturbance-dependent species, with disturbance creating the diverse, highly interspersed habitat that quail require known as the "Crazy Quilt." Ideally, this quilt contains small patches of nesting cover (bunchgrasses such as bluestems), foraging and brood-rearing habitat (weeds such as ragweed and partridge pea), and escape cover (shrubs such as saw palmetto and wax myrtle) mixed among each other in roughly equal amounts.

Whether it is pine flatwoods, dry prairie, or any other type of native range, as grazing intensity changes so does the plant community. When applied properly, grazing can promote quality quail habitat. As grazing intensity increases, the preferred native grasses decrease in abundance, while less palatable grasses and forbs become more abundant and widely distributed. Often thought of as weeds, many of these species produce and attract abundant and nutritious quail foods, such as seeds and insects, while providing excellent foraging cover and some escape cover. The increased soil disturbance from livestock hooves may also improve soil conditions for weed species, accelerating their establishment. In addition, shrubs and woody vegetation

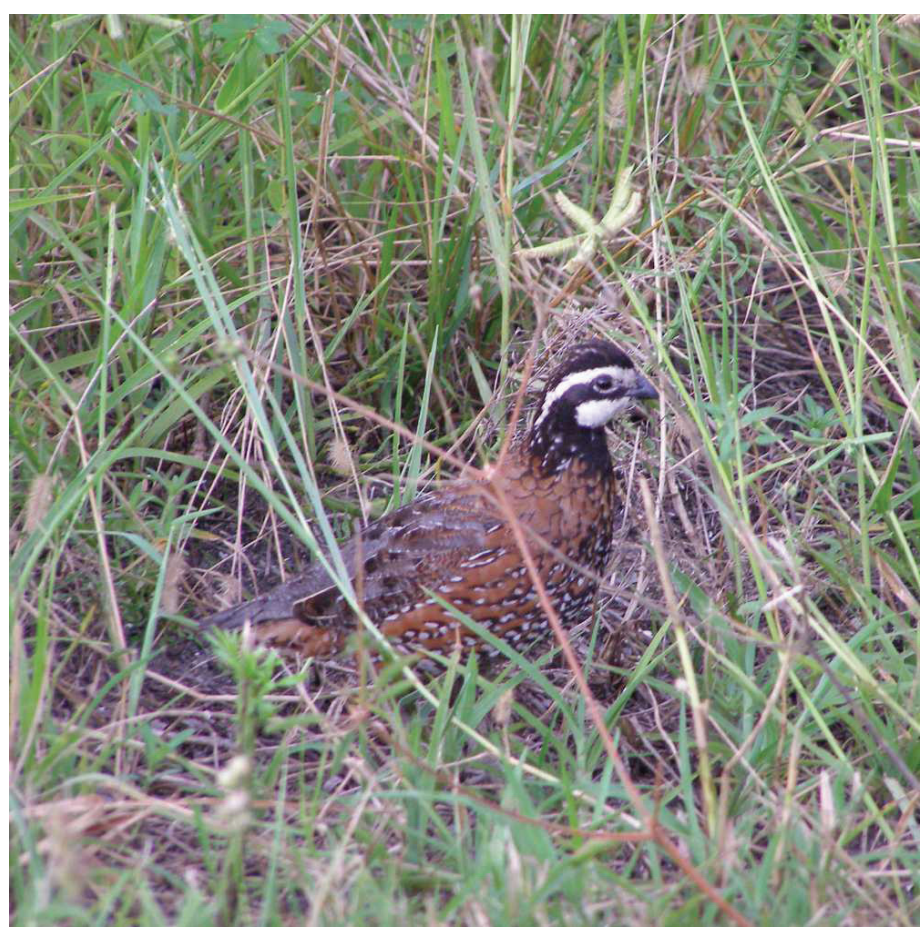

Figure 1. Male northern bobwhite.

Credits: William Giuliano

begin to proliferate as competition from native grasses is reduced by grazing. These types of plants are valuable for quail as escape cover from both predators and weather. Moderate levels of grazing lead to a more open and diverse rangeland community producing the best quail habitat and fair to good livestock forage conditions. Unfortunately, there is no magic stocking rate or number of animal units

1. This document is WEC332, one of a series of the Wildlife Ecology and Conservation Department, Florida Cooperative Extension Service, Institute of Food and Agricultural Sciences, University of Florida. Original publication date January 2013. Visit the EDIS website at http://edis.ifas.ufl.edu.

2. William M. Giuliano, professor; and Lauren Watine, student; Department of Wildlife Ecology and Conservation, University of Florida, Gainesville, FL 32611. 
that will always provide moderate grazing intensity. How many animals are needed, how long they graze, how often they are in an area, and at what time of year are all factors that need to be considered; all will change from one pasture to the next because of differences in soil conditions, vegetation, and climate. Other land management practices such as prescribed fire, roller chopping, and disking are often used in rangelands to enhance livestock forage production when stocking rates are high and to disturb the system to enhance quail habitat. Areas of "improved" pasture, where large monocultures of exotic forage grasses such as Bahia grass have been established, are of almost no value to quail and should not be promoted. If these are present, livestock should be managed on these areas, with native range kept for quail. Below are specific tips to improve quail habitat that focus on diversifying the plant species and structural composition and increasing early successional communities dominated by herbaceous plants.

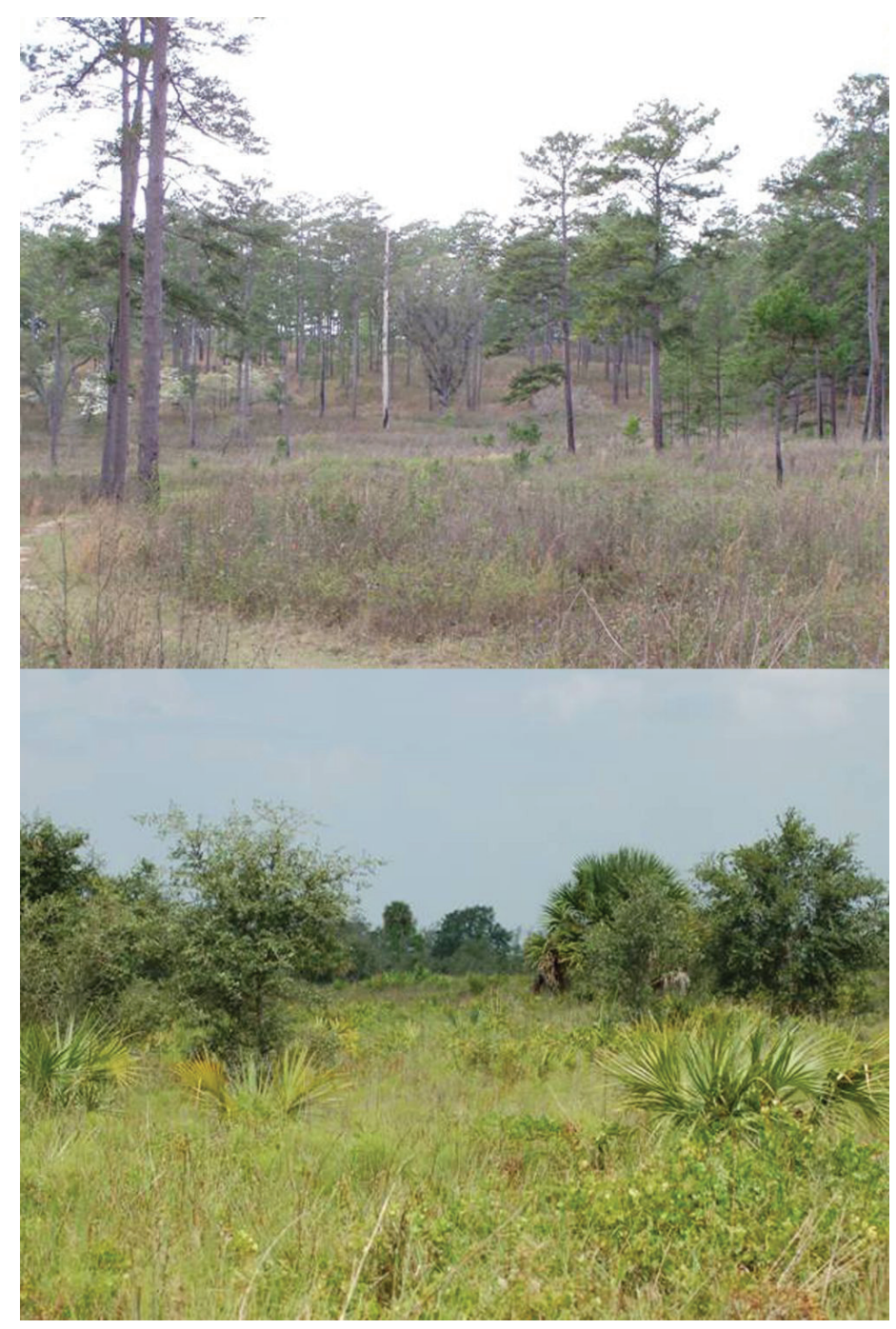

Figure 2. Quail prefer a highly interspersed, "crazy quilt" habitat. Credits: William Giuliano

\section{Tips}

- Use rotational rather than continuous grazing systems; rotate livestock onto improved range during quail nesting season (April-June).

- Adjust stocking rates to moderate levels for the specific system.

- Use short duration-low frequency grazing to minimize the time and frequency livestock are disturbing birds and allowing more time for plant growth.

- Time grazing in an area to avoid the nesting season (April-June), allow plant regrowth prior to nesting, and produce seeds for food.

- Use mobile heavy spot grazing by temporarily fencing livestock in small areas or attracting dense concentrations of animals to water sources, salt, supplements, hay, or recently burned areas to disturb soil, overgraze, and provide excessive nutrient (feces) inputs that will lead to weedy areas when stock are removed

- When converting areas from native to improved pasture, improve 100- to 200-yard-wide strips that alternate with native range.

- Temporarily exclude livestock from small areas to create weed patches.

- Let the weedy and shrubby vegetation grow along pasture boundary fences.

- Disturb the soil and ground cover by burning, rollerchopping, disking, or any other method.

- Manage food plots (1-3 acres each; $>3 \%$ of the land) containing primarily forbs (especially legumes) with some grasses during both cool and warm seasons.

- Maintain odd areas such as ditches, roadsides, etc.

These recommendations should be considered in the context of the overall system. For example, when locating a food plot consider putting it near an improved pasture, which has no food or cover value for quail, rather than a fallow field. An extensive discussion and descriptions of the tips provided here can be found in Bobwhite Quail in Florida: Ecology and Management by W.M. Giuliano, J.F. Selph, and B.J. Schad available through the UF/IFAS Extension Bookstore (http://ifasbooks.ifas.ufl.edu). 